\title{
A Consistent Córrelation for Three Phase Relative Permeabilities and Phäse Pressures Based on Three Sets of Two Phase Data
}

\author{
Hustad O. St., Hansen A. G
}

IKU, Norway

\footnotetext{
Copyright 1995, Steering Committee of the European IOR - Symposium.

This paper was presented at the 8th. European IOR - Symposium in Vienna, Austria. May 16 - 17, 1995

This paper was selected for presentation by the Steering Committee, following review of information contained in an abstract

submitted by the author(8). The paper, as presented has not been reviewed by the Steering Committee.
}

\begin{abstract}
A correlation for three-phase relative permeabilities and phase pressures for reservoir simulators is presented. The formulation is based on three sets of two-phase data and properly accounts for six, two-phase, residual or critical saturations. The model uses only two-phase data and an interpolation technique to obtain three-phase properties by a systematic weighing procedure based on the saturations and end point values. The procedure ensures smooth transitions of relative permeabilities and phase pressures for processes that go from any two-phase state to another twophase state by way of the three-phase region.
\end{abstract}

Successful simulations with the correlation are shown and compared to results from a vertical gas flooding experiment exhibiting three-phase flow and having extensive gas injection.

\section{Introduction}

Within the SPOR program (The Norwegian State R\&D Program for Improved Oil Recovery and
Reservoir Technology, 1985-1991), ${ }^{1}$ two vertical gas flooding experiments were performed at reservoir conditions, followed by simulations. ${ }^{2}$ In the follow-up research program, RUTH (Reservoir Utilization Through Advanced Technological Help, 1992-1995), the Gas Flooding subprogram, studies of core flooding experiments and simulations have continued. In particular, mechanisms such as film flow, which affect residual oil saturation, have been investigated in order to improve the simulation capability of residual saturations. ${ }^{3,4}$

Production profiles and saturation distributions from vertical gas flooding experiments with three mobile phases, have shown to be difficult to reproduce in simulations. The simulations are even more difficult when extensive changes in interfacial tensions and cycles of imbibition and drainage are present.

A vertical gas flooding experiment at near ambient conditions, similar to the experiments performed within the SPOR program, has been performed. The aims were to obtain data and investigate how two-phase relative permeabilities and capillary 
pressures may be applied when simulating processes exhibiting three-phase flow near residual oil saturation and having "film flow" behavior.

The state of the art formulation for three-phase relative permeabilities and phase pressures ${ }^{5}$ has shown to be difficult to apply, honoring measured petrophysical data, and at the same time reproducing dynamic experimental observations from core floods. ${ }^{2}$ The assumptions on which the state of the art formulations for relative permeability and phase pressure are based, are therefore reviewed. Thereafter a discussion is made, arguing the need for improvements.

In the state of the art formulation for three-phase relative permeabilities typical for most simulators, the relative permeabilities for the wetting and nonwetting phases (water and gas) depend on their own saturations. The relative permeability to water is usually measured with mobile oil and without the presence of gas. It is assumed however, applicable for all values of gas saturation. Likewise, the relative permeability to gas is often measured in the presence of mobile oil and irreducible water, but assumed applicable for all values of water saturation. The relative permeability to oil is made dependent on two saturations. Its functional dependency has been suggested by several authors and is nicely summarized in Reference 6 . The three-phase functional form is based on two-phase properties where the wetting and non-wetting phases have a particular role. Exceptions to this formulation exist for processes describing, for example, miscible flow and chemical flooding.

Capillary pressures, defined as the pressure difference between two-phases, are applied as constraints to link the phase pressures. In the state of the art formulation, capillary pressures are assumed functions of one saturation. For example, the oil-water capillary pressure is assumed dependent on water saturation, and the gas-oil capillary pressure is assumed dependent on the gas saturation. Note that the third gas-water capillary pressure is defined by the first two capillary pressures. $^{5}$

During a simulation, the gas-oil capillary pressure is also made dependent on the gas-oil interfacial tension while the oil-water-capillary pressure is assumed dependent on the water saturation alone.

On the length scales relevant for core flooding experiments, capillary pressures have à large influence on the flow. The magnitude of the oilwater capillary pressure, for example, has a decisive influence on the wetting water phase's level of recovery.

The phase pressure gradient of a particular mobile phase and the very low values of relative permeability becomes important when that phase approaches the conditions of no flow. Experience from simulating core flooding experiments using the state of the art formulation shows that varying the relative permeability's end point values and magnitude has less influence on the simulated residual saturation than capillary pressure. This is due to the differential pressure between the inlet and outlet of the core, and the distribution of phase pressures within the core (saturation distribution).

It is observed that when applying the state of the art formulation for three-phase flow, only part of the measured gas-oil capillary pressure curve is used, ${ }^{2}$ and the capillary pressure values having high gas saturations are not used. This leads to lower gas saturations in simulations than what often is observed in core floods. ${ }^{4}$

In principle the flowing rate of a particular phase in the presence of other phases depends on the other phases' pressure gradients, ${ }^{3,7}$ i.e. the "piggy back" phenomenon, for example, in film flow. This formulation has not been pursued here due to the difficult task of measuring the full coupling matrix of relative permeabilities. Instead, attempts are made to correlate measured two-phase data to three-phase flow and residual saturations.

One can observe that different fluid systems will produce different capillary pressure curves having different shapes and end point values, ${ }^{2,4}$ the end point value being defined as the saturation value where the capillary pressure becomes "infinite" or a maximum value which is large enough for the process under consideration. The end point values are the same for relative permeabilities as for the capillary pressures. A ternary diagram is shown in Figure 1, where the two-phase capillary pressures have been illustrated by the curves within the boxes along the sides of the ternary diagram. The figure illustrates how the end points may be chosen and the region of the three-phase space (shaded) where the phases (one, two or three) flow.

Information obtained along the gas-oil and oilwater axes of the ternary diagram, see Figure 1, is of less relevance for saturations near the gas-water axis, where residual oil saturations occur. 


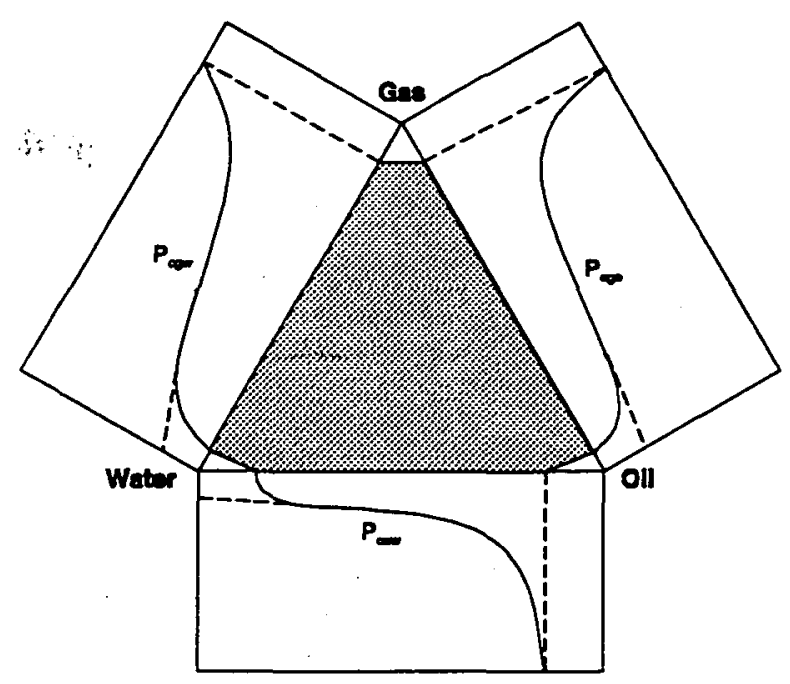

\section{Figure 1 Two phase capillary pressure representation on a ternary diagram.}

If the non-wetting gas phase should come in contact with the wetting water phase, it is obvious that the gas-water relative permeabilities and capillary pressure will be important for the flowing process.

The above experiences, ${ }^{2,3,4}$ observations and arguments have been a motivation to construct a consistent relative permeability and phase pressure formulation for three-phase flow that honors all three two-phase conditions.

In particular, incorporating the gas-water capillary pressure in reservoir simulators should be relevant for gas condensate systems that undergo liquid condensation and for processes that go miscible.

Three-phase systems where the gas and oil pass through the fluids' critical region (miscibility), are often described by gas and oil relative permeabilities that become equal to their respective saturations. The state of the art formulation is inadequate here and requires a more consistent formulation, especially when water is present. At miscible conditions the gas-oil capillary pressure is zero. If water is present with one hydrocarbon phase, there exists a hydrocarbon-water capillary pressure, and the relative permeability (gas or oil) is not necessarily equal to its saturation. If the critical hydrocarbon phase is denoted as a gas, there is a need for the gas-water relative permeabilities and capillary pressure. For hydrocarbon systems that approach the near critical or miscible condition from an immiscible state, the relative permeability to gas (gas-water system) must be equal to the relative permeability to oil (oil-water system) when rapid labeling changes occur between gas and oil in reservoir simulators.

Gas condensate systems and miscible processes are not further discussed in this paper.

\section{Three-phase relative permeabilities}

The idea behind the proposed formulation is to estimate three-phase relative permeabilities by using two-phase relative permeability values in a weighing scheme dependent on the saturations of the system. The weighing scheme ensures a smooth transition of the end points from one twophase state to another.

The discussion will concentrate on the formulation for the oil phase relative permeability. Equivalent formulations may be derived for the other phases.

A typical ternary diagram is illustrated in Figure 2, where the relevant oil two-phase end point values are indicated, Sorg, $S_{g r o}, S_{o r w}$ and $S_{w r o}$. The end point values may or may not be equal to one another.

Straight lines may be drawn to connect two end point saturations. These lines connect the twophase end points representing the minimum and maximum oil saturations for oil flow. Straight lines are chosen here for simplicity. Curved lines that give unique intersection points may equally be chosen to connect the end points if so desired.

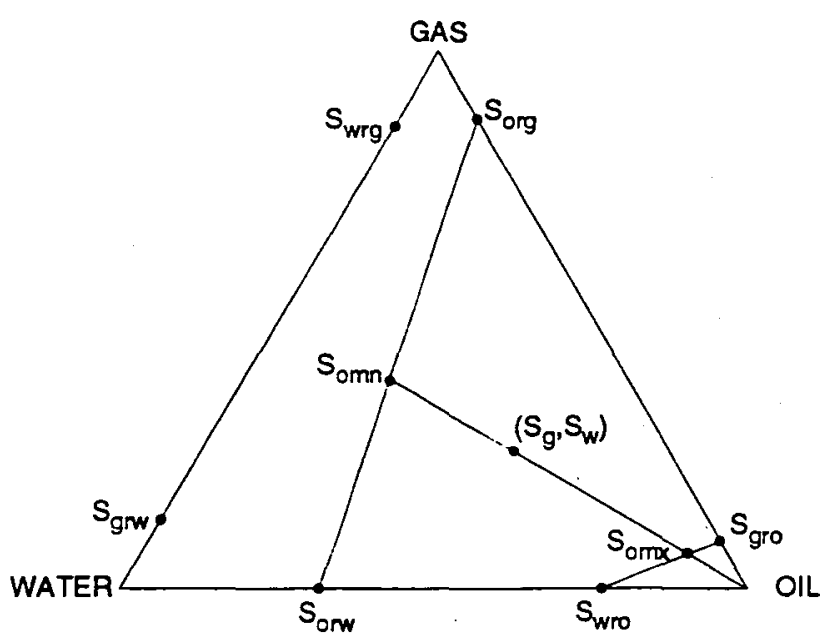

Figure 2 Ternary diagram showing typical end point values for oil relative permeability. 
Given the three-phase saturations, labeled $\left(S_{g}, S_{w}\right)$ in Figure 2, draw a straight line running through this point and the oil apex. This defines two intersection points with the lines connecting the end point values. The associated oil coordinates to the intersection points are represented by $S_{o m n}$ and Somx. These values represent the minimum and maximum oil saturations for the three-phase saturations, and are given by

$S_{\text {omn }}=\frac{S_{w} S_{o r w}+S_{g} S_{o r g}+S_{o r g} S_{o r w}\left(S_{o}-1\right)}{S_{g}\left(1-S_{o r w}\right)+S_{w}\left(1-S_{o r g}\right)}$

and

$S_{o \text { mx }}=\frac{S_{w} S_{g \mathrm{ro}}+S_{g} S_{\text {wTo }}+S_{g \mathrm{ro}} S_{\text {wTo }}\left(S_{o}-1\right)}{S_{g} S_{\text {wTo }}+S_{w} S_{g \mathrm{ro}}}$

The corresponding normalized three-phase oil saturation is then

$$
\mathrm{S}_{o}^{*}=\frac{\mathrm{S}_{o}-\mathrm{S}_{o \mathrm{mn}}}{\mathrm{S}_{o \mathrm{mx}}-\mathrm{S}_{o \mathrm{mn}}} .
$$

The normalized oil saturation may then be used to obtain representative two-phase oil relative permeabilities from normalized two-phase relative permeabilities:

and

$$
\hat{\mathbf{k}}_{\mathrm{rog}}=\mathbf{k}_{\mathrm{rog}}^{\mathrm{n}}\left(\mathrm{S}_{o}^{*}\right)
$$

$$
\hat{\mathbf{k}}_{\text {row }}=\mathbf{k}_{\text {row }}^{\mathbf{n}}\left(S_{o}^{*}\right) \text {. }
$$

The superscript $\mathrm{n}$ indicates that the relative permeabilities are normalized to saturation values between zero and one.

Lastly, these representative two-phase oil relative permeabilities may be weighed by the saturations in the three-phase region to obtain the three-phase oil relative permeability,

$$
\mathrm{k}_{\mathrm{r} o}=\frac{\mathrm{S}_{w}}{\mathrm{~S}_{g}+\mathrm{S}_{w}} \hat{\mathrm{k}}_{\mathrm{row}}+\frac{\mathrm{S}_{g}}{\mathrm{~S}_{g}+\mathrm{S}_{w}} \hat{\mathrm{k}}_{\mathrm{rog}} .
$$

For a two-phase system, the three-phase oil relative permeability is equal to the two-phase oil relative permeability.

This formulation then takes" into account the end point values of all the two-phase systems.

The saturations fulfill the condition,

$$
S_{g}+S_{o}+S_{w}=1
$$

but note that the normalized saturations do not necessarily sum to unity, i.e.

$$
S_{g}^{*}+S_{o}^{*}+S_{w}^{*} \neq 1
$$

\section{Phase pressure relationships}

Turning now to the three sets of two-phase capillary pressures, a similar approach as with the three-phase relative permeabilities is applied when determining the phase pressures. That is to say, they are based on two-phase data. Denote the three representative two-phase capillary pressure values by

$$
\begin{aligned}
& \hat{\mathrm{P}}_{\mathrm{cgw}}=\mathrm{P}_{\mathrm{cgw}}^{\mathrm{n}}\left(\mathrm{S}_{g}^{*}\right), \\
& \hat{\mathrm{P}}_{\mathrm{cgo}}=\mathrm{P}_{\mathrm{cgo} o}^{\mathrm{n}}\left(\mathrm{S}_{g}^{*}\right)
\end{aligned}
$$

and

$$
\hat{\mathrm{P}}_{\text {cow }}=\mathrm{P}_{\text {cow }}^{\mathrm{n}}\left(\mathrm{S}_{w}^{*}\right) \text {, }
$$

where the superscript $\mathbf{n}$ represents the normalized value. The representative two-phase capillary pressures do not necessarily fulfill the constraint

$$
\hat{\mathrm{P}}_{\mathrm{cgw}}-\hat{\mathrm{P}}_{\mathrm{cgo}}-\hat{\mathrm{P}}_{\mathrm{cow}}=0 \text {. }
$$

To meet this constraint, it is suggested to modify the capillary pressures in a manner that reflects their relative position in the three phase region. In addition, they must equal the true two-phase values when the system becomes two phase. The following weighing of the representative twophase capillary pressures is suggested to define the three-phase capillary pressure values:

$$
\begin{aligned}
& \mathrm{P}_{c g o}=\hat{\mathrm{P}}_{c g o}+\mathrm{S}_{w}\left(\hat{\mathrm{P}}_{\mathrm{cgw}}-\hat{\mathrm{P}}_{\mathrm{cgo}}-\hat{\mathrm{P}}_{\mathrm{cow}}\right) \\
& \mathrm{P}_{c o w}=\hat{\mathrm{P}}_{c o w}+\mathrm{S}_{g}\left(\hat{\mathrm{P}}_{\mathrm{cgw}}-\hat{\mathrm{P}}_{\mathrm{cgo}}-\hat{\mathrm{P}}_{c o w}\right) .
\end{aligned}
$$$$
\text { and }
$$

This definition implies that

$$
\mathrm{P}_{c g w}=\hat{\mathrm{P}}_{\mathrm{cgw}}-\mathrm{S}_{o}\left(\hat{\mathrm{P}}_{\mathrm{cgw}}-\hat{\mathrm{P}}_{\mathrm{cgo}}-\hat{\mathrm{P}}_{\mathrm{cow}}\right)
$$

in order to meet

$$
\mathrm{P}_{\text {cgw }}=\mathrm{P}_{\text {cgo }}+\mathrm{P}_{\text {cow }} \text {. }
$$


This definition ensures a smooth transition of phase pressures between any two-phase state and the three-phase stâte:

To relate the intermediate (oil) pressure to the other phase pressures, Equations 13 and 14 are applied:

$$
\begin{aligned}
& \mathrm{p}_{g}=\mathrm{p}_{o}+\mathrm{P}_{\mathrm{cgo}} \\
& \mathrm{p}_{w}=\mathrm{p}_{o}-\mathrm{P}_{\text {cow }}
\end{aligned}
$$

The above formulation, as it is posed, requires no three-phase data and makes use of all three sets of measured two-phase data. The two-phase data as applied below is without the third immobile phase. However, the correlation may be extended to include a fixed saturation value of the third immobile phase.

\section{Use of two-phase data in simulations}

The proposed formulation has been programmed into an IMPES type compositional simulator, ${ }^{8}$ based on table look-up values for two-phase relative permeabilities and capillary pressures (rock curves). Several table sets may be entered, representing various parts of the core flooding regions. In addition, end point saturation values may be entered for each grid block, permitting a simple transformation of the rock curves from reference table values to grid block values.

The six end point saturations defined for a particular grid block, $S_{i r j}$, may be dependent on, for example, interfacial tension:

$$
\mathrm{S}_{i \mathrm{rj}}=\mathrm{S}_{i \mathrm{rj}}\left(\sigma_{i j}\right) \text {, }
$$

where $i$ and $j$ represent the two phases involved. This equation may be applied to residual saturations for individual grid blocks, but precaution should be exercised when transforming end point values to systems significantly different from the reference system. This may require a scheme as suggested in Reference 9. It has been observed that small changes to some grid block residual saturations will lead to altered recovery functions because of transformation between grid block and table values.

The Macleod-Sugden correlation is used for calculation of gas-oil interfacial tensions, ${ }^{10}$ while the correlation of Reference 11 was tested for gaswater and oil-water interfacial tensions.
Satisfactory interfacial tensions were obtained for the oil-water (n-octane-water) system. However, the correlation was not developed for and does not give satisfactory values for the nitrogen-water interfacial tension, which was required for the system used in this study, i.e. nitrogen, n-octane and water.

Hysteresis is treated with separate rock curves for each process simulated, first drainage, imbibition and second drainage. Hysteresis models, as for example that suggested in Reference 12 , have not been applied.

Two-phase capillary pressures are scaled by the ratio of interfacial tensions:

$$
\mathrm{P}_{c i j}^{\mathrm{n}}=\frac{\sigma_{i j}}{\sigma_{i j}^{\mathrm{r}}} \mathrm{P}_{c i j}^{\mathrm{nr}},
$$

where superscript $\mathrm{nr}$ represents the normalized reference condition and superscript $\mathrm{n}$ represents the normalized reservoir condition. This scaling procedure may be applied as long as there is no redistribution of fluids within the pores due to changes in interfacial tension. In simulations, this scaling will alter the capillary pressure function which influences the saturation distributions.

\section{Simulation of a core flood experiment}

The proposed formulation has been applied in simulation of a core flood experiment, labeled e, in Reference 13 , namely gas injection into a vertical core after water injection at $0.6 \mathrm{MPa}$ and $293.15 \mathrm{~K}$.

The saturation history of the core is as follows: Oil was first injected into $100 \%$ water saturated core while in a horizontal position until water production stopped. Water injection was then performed, injecting at the same end of the core, until no oil production. The core was then tilted to a vertical position and gas was injected at the top of the core. All the injections were at the same end of the core. The injection rates and cumulative amounts are listed in Table 1.

The simulations performed have followed the same saturation history as described above, using a ID grid having 20 grid blocks. Two of these grid blocks represented the dead end volumes outside the core, one on each end. Simulations having up to 182 grid blocks have been performed without showing significant difference in the results. Therefore 20 grid blocks were chosen, because of the lower cpu requirements. 
A summary of the model's fluid composition and equation of state (EOS) parameters is given in Table 2.

Table 1 Flooding sequence and core properties..

\begin{tabular}{|c|c|c|}
\hline $\begin{array}{c}\text { Injection } \\
\text { Fluid }\end{array}$ & $\begin{array}{c}\text { Rate } \\
\left(\mathrm{cm}^{3} / \mathrm{hr}\right)\end{array}$ & $\begin{array}{c}\text { Pore vol. } \\
\text { injected }\end{array}$ \\
\hline Oil & 60.0 & 3.0 \\
Water & 60.0 & 2.9 \\
Gas & 5.08 & 62.0 \\
\hline
\end{tabular}

Core length, diameter: $60.9 \mathrm{~cm}, 3.8 \mathrm{~cm}$

Porosity, permeability: $23.2 \%, 2.46 \mu^{2}$

Temperature, back pressure: 293.15 K, $0.6 \mathrm{MPa}$

Table 2 Soave-Redlich-Kwong equation of state parameters.

\begin{tabular}{|l|c|c|}
\hline \multirow{2}{*}{\multicolumn{1}{c|}{ EOS }} & \multicolumn{2}{|c|}{ Component } \\
\cline { 2 - 3 } parameter & $\mathrm{N}_{2}$ & $\mathrm{n}-\mathrm{C}_{8}$ \\
\hline Mole fraction & 0.0084 & 0.9916 \\
$\mathrm{MW}(\mathrm{g} /$ mole $)$ & 28.013 & 114.232 \\
$\mathrm{P}_{\mathrm{c}}(\mathrm{MPa})$ & 3.4 & 2.488 \\
$\mathrm{~V}_{\mathrm{c}}\left(\mathrm{cm}^{3} /\right.$ mole $)$ & 89.89 & 492.06 \\
$\mathrm{~T}_{\mathrm{c}}(\mathrm{K})$ & 126.26 & 568.83 \\
Acentric factor & 0.0358 & 0.3998 \\
Racket Z-factor & 0.2900 & 0.2571 \\
Parachor & 41.0 & 352.0 \\
\hline
\end{tabular}

Experimental capillary pressures were entered as table values representing the core grid blocks. At the inlet and outlet grid blocks the capillary pressures were set to zero.

For the water injection process, an imbibition capillary pressure (oil-water system) was estimated to reproduce the core's total residual oil saturation from that process. A second oil-water drainage capillary pressure curve was also estimated. These capillary pressures are presently being measured.

Relative permeabilities were taken from References 2 and 4 . Adjustments were made to the low relative permeability values $\left(<10^{-3}\right)$, in order to improve the match of the recoveries. The end point values used are shown in Table 3 and they are the same for the tables as for the grid blocks. The relative permeability iso-values for the three phases are shown in Figure 3.
Table 3 End point saturations.

\begin{tabular}{|c|c|c|}
\hline Water & Oil & Gas \\
\hline $\mathrm{S}_{w \mathrm{ro}}=0.126$ & $\mathrm{~S}_{\text {orw }}=0.17$ & $\mathrm{~S}_{g \mathrm{rw}}=0.0001$ \\
$\mathrm{~S}_{w \mathrm{rg}}=0.005$ & $\mathrm{~S}_{\text {org }}=0.035$ & $\mathrm{~S}_{\text {gro }}=0.0001$ \\
\hline
\end{tabular}

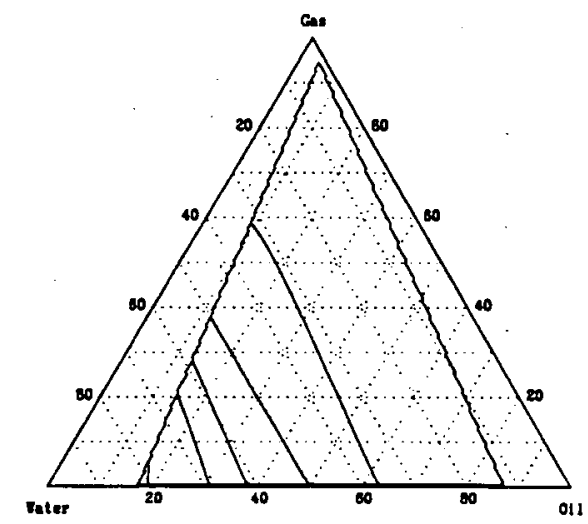

a) Water relative permeability (contour 0.3 not shown)

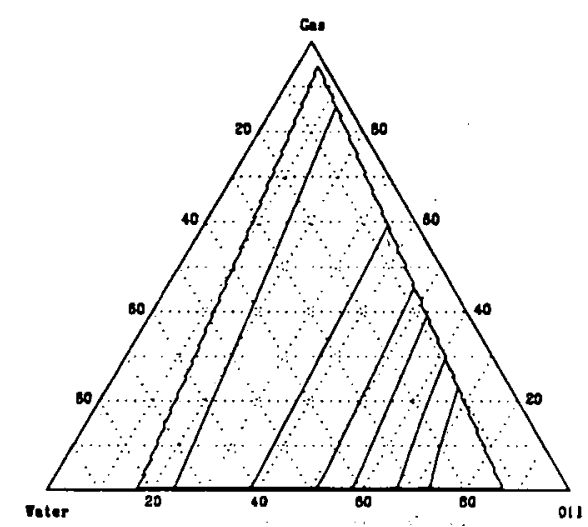

b) Oil relative permeability

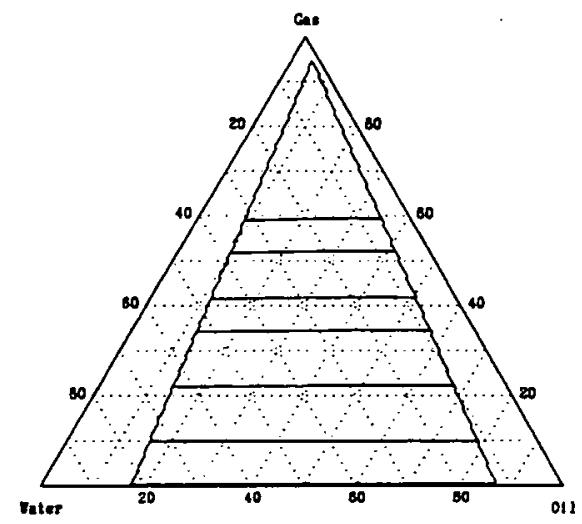

c) Gas relative permeability

Figure 3 Relative permeability iso-values; $0.0001,0.01,0.05,0.1,0.2$ and 0.3 . 
It may be mentioned here that the relative permeabilities may be different if obtained from steady state of dynamic experiments, for systems having high interfacial tensions. ${ }^{14}$ This has also been observed while matching this experiment. The two-phase relative permeability curves used in the gas injection simulations are shown and compared to experimental values in Figure 4.

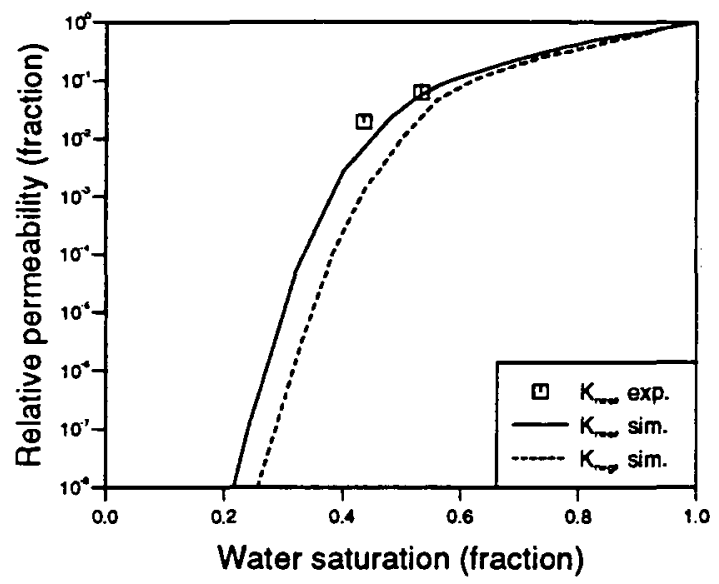

a) Water relative permeabilities.

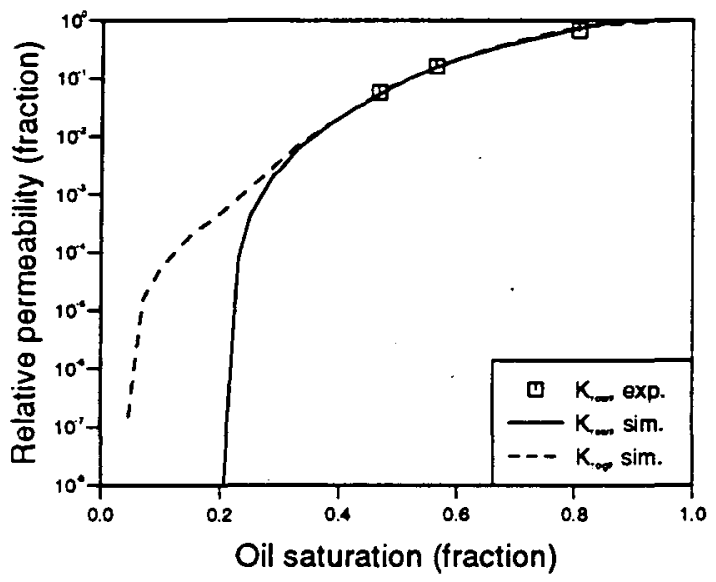

b) Oil relative permeabilities.

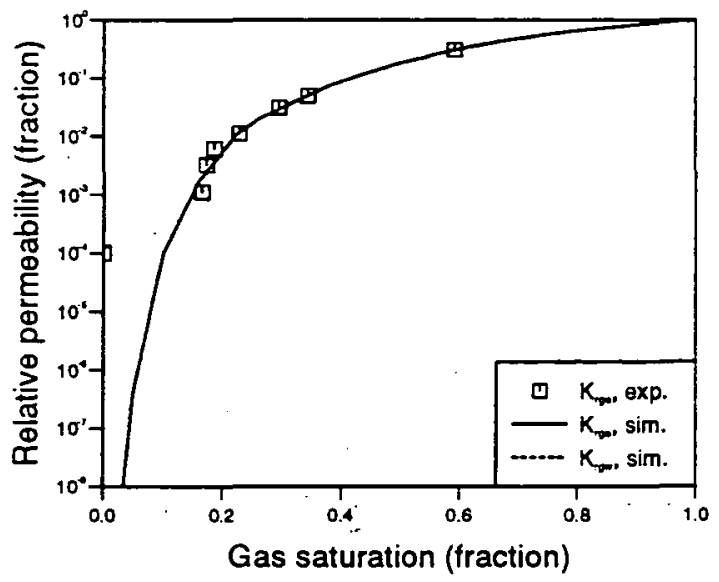

c) Gas relative permeabilities.

Figure 4 Two-phase relative permebilities.
Gas-oil and oil-water capillary pressure iso-curves (Equations 13 and 14) are shown in Figure 5. Note that the iso-values are not along a constant saturation value, as for the state of the art formulation. The gas-oil capillary pressure isovalues run along "constant" oil saturation values instead of along constant gas saturations. This is due to the high two-phase gas-water capillary pressure values compared to the two-phase gas-oil capillary pressure values. The two-phase capillary pressure curves are shown in Figure 6.

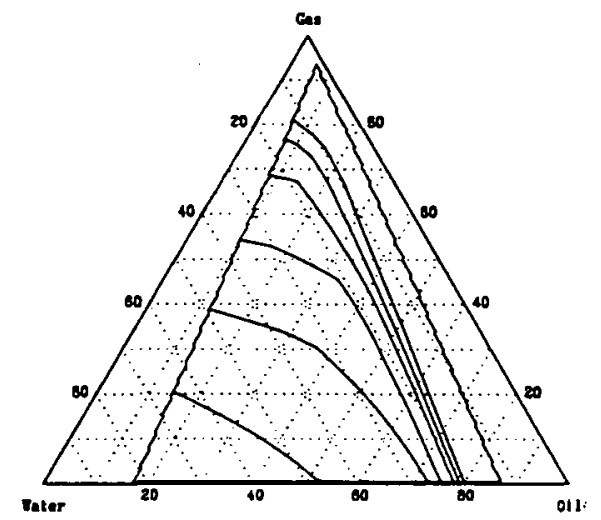

a) Oil-water. Contours: 0.03, 0.04, 0.05, 0.06, 0.07 and 0.08 .

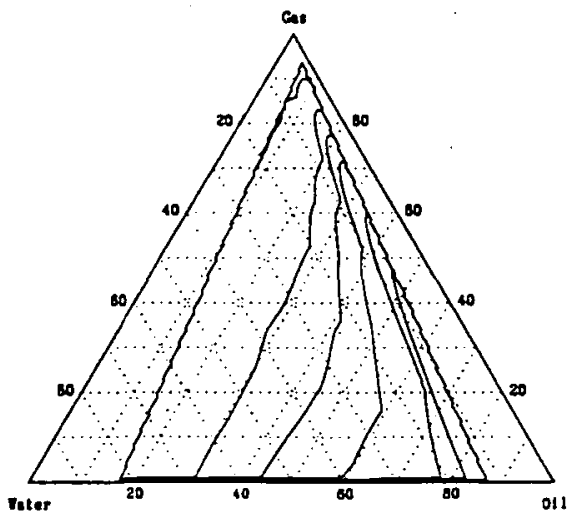

b) Gas-oil . Contours: 0.001, 0.01, 0.02, 0.025, 0.03 and 0.04 .

Figure 5 Unscaled capillary pressure isovalues.

Figure 7 shows the experimental (markers) and simulated (lines) recoveries from the first drainage process, oil injection into $100 \%$ water saturated core. Figure 8 shows the experimental and simulated recoveries from the following imbibition process. For the first drainage and imbibition processes the oil-water capillary pressure was scaled (see Equation 19) by the interfacial tension ratio of 50.8/37.1 (n-octane-water/n-decane-water). 


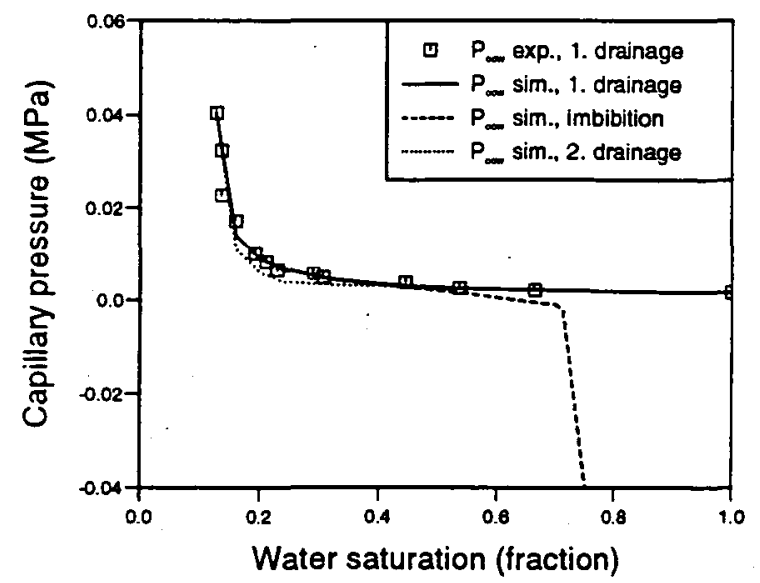

a) Oil-water capillary pressure.

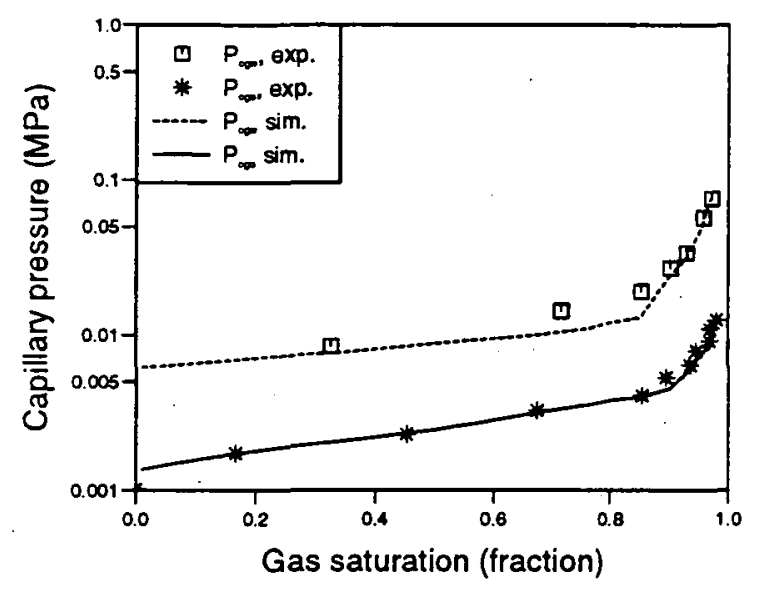

b) Gas-oil and gas-water capillary pressures.

Figure 6 Two-phase capillary pressures.

The recoveries from the vertical gas injection process are shown in Figure 9. Two oil recoveries are shown, one at standard conditions (dotted line) and the other at $0.6 \mathrm{MPa}$ (solid line). Note that this formulation is able to model the gradual increase of oil recovery (at $0.6 \mathrm{MPa}$ ) throughout the time period. As may be seen by the oil recovery at standard conditions, the equation of state can give erroneous phase volumes when performing the flash calculation from $0.6 \mathrm{MPa}$ to $0.1 \mathrm{MPa}$, even for this simple two component system. This is due to the small quantities (overall mole fraction) of $n-$ octane produced from the film flow process. An overall mole fraction of n-octane less than $1.3 \%$ in the producing stream can have a small liquid phase fraction at $0.6 \mathrm{MPa}$ but will result in pure vapor phase at ambient conditions: The dew point here contains slightly more n-octane at standard conditions compared to conditions of $0.6 \mathrm{MPa}$. No noticeable difference was observed for the water recovery at these two conditions.

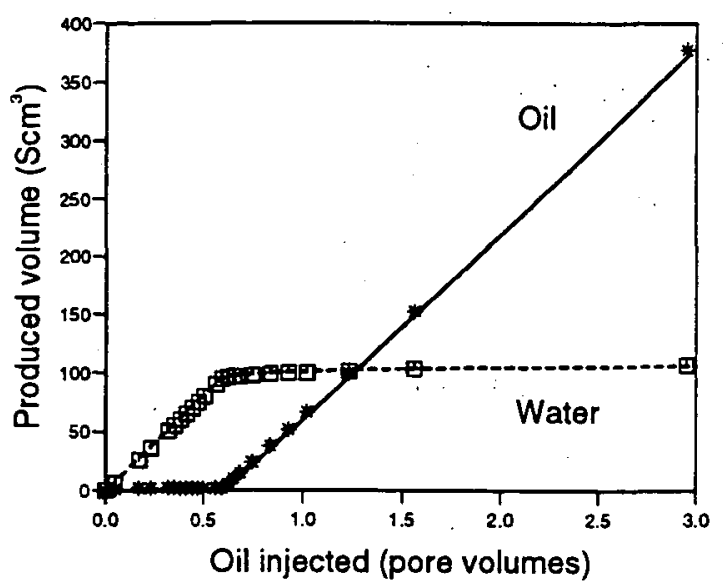

Figure 7 Experimental and simulated recoveries from oil injection (first drainage) process.

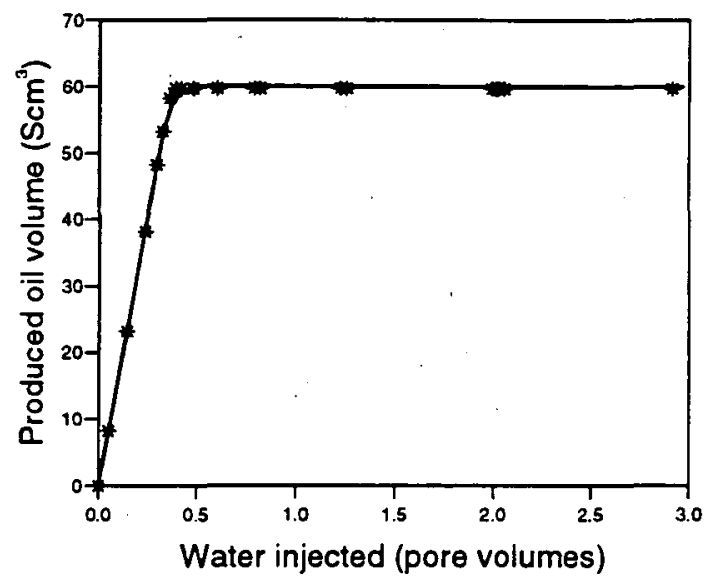

Figure 8 Experimental and simulated recoveries from water injection (imbibition) process.

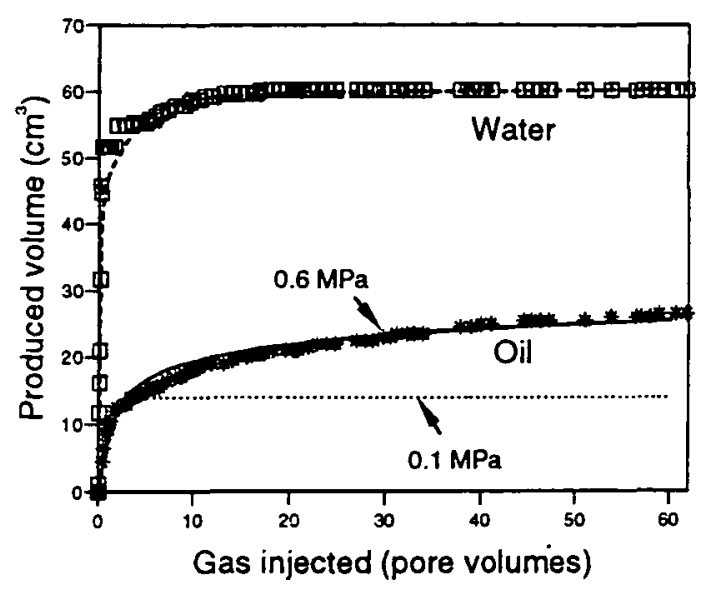

Figure 9 Experimental and simulated recoveries from gas injection (second drainage) process. 
To achieve this match of the recoveries, the gaswater capillary pressure values had to be scaled by the interfacial tension ratio of 39.6/72.0. Scaling the capillary pressures may result in significantly different iso-values as shown in Figure 10. Here the gas-water, gas-oil and oil-water interfacial tension ratios are $0.55,0.92$ and 1.37 , respectively. The saturation distribution is very sensitive to the capillary pressure functions and the gas-water interfacial tensions are of most importance here.

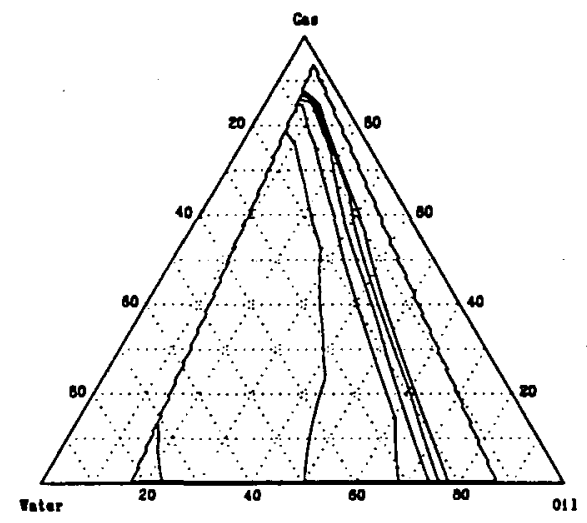

a) Oil-water. Contours: 0.03, 0.04, 0.05, 0.07 and 0.08 .

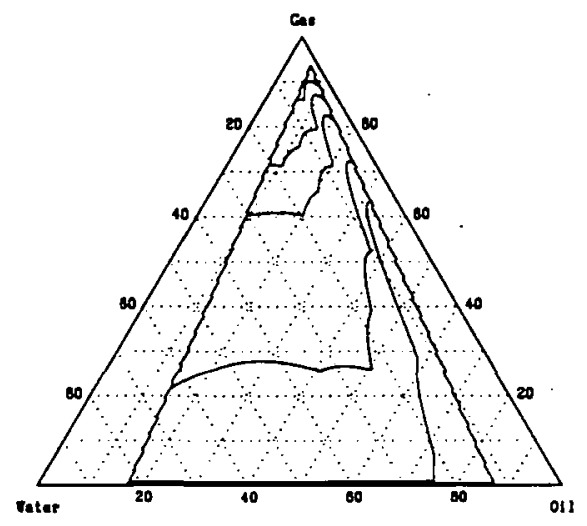

b) Gas-oil. Contours: 0.001, 0.01, 0.02, 0.025, 0.03 and 0.04 .

\section{Figure 10 Scaled capillary pressure iso- values.}

The final saturations within the core are shown as saturation vs. height and in a ternary representation, respectively, in Figure 11. The experimental uncertainty is illustrated by the horizontal lines in Figure 11a and dashed lines in Figure 11b. The values are at 62 pore volumes. injected (PVI). Note the high values of gas saturation in the upper part of the core. It may also be seen that this correlation is able to model a slight increase in oil saturation with increasing water saturation. This is therefore an improvement from the state of the art formulation, which models the intermediate oil saturation as a "constant" value with depth. Better saturation profiles have been achieved than what is shown here, but the water recovery was too high.

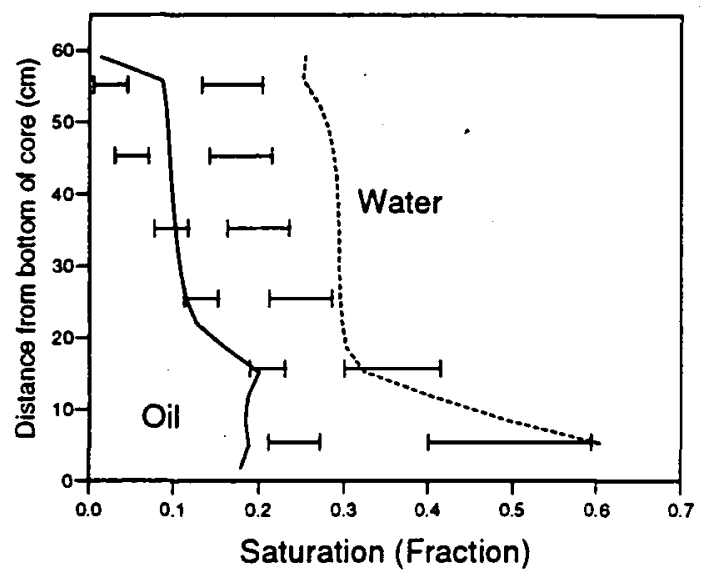

a) Versus height.

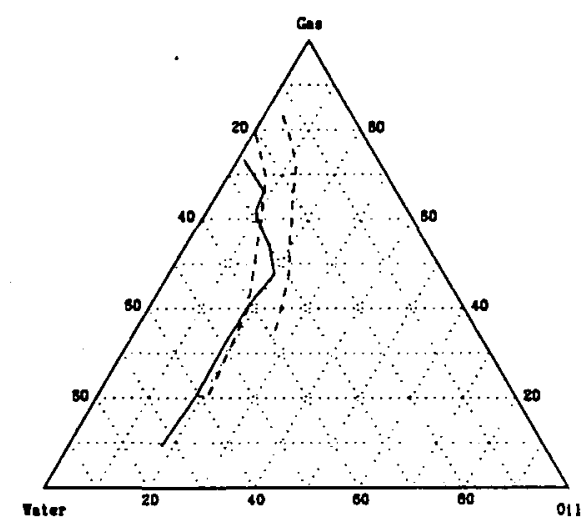

b) Ternary representation.

\section{Figure 11 Experimental and simulated saturation profiles at 62 PVI.}

\section{Conclusions}

The following conclusions are made:

1. A formulation has been presented for relative permeabilities and phase pressures to describe three-phase flow that takes into use three sets of two-phase relative permeabilities and capillary pressures.

2. Compositional simulation using the proposed formulation was able to model oil recovery having film flow behavior.

3. The formulation permits the simulation of high gas saturation.

4. Simulated recoveries compare well to experimental recoveries.

5. Saturation profiles were difficult to reproduce by simulations and were very sensitive to the two-phase capillary pressure functions. 


\section{Nomenclature}

k - relative permeability

$\hat{k} \quad$ - representative relative permeability

$\mathrm{p}$ - pressure

$P_{c g o}$ - capillary pressure, gas-oil

$\mathrm{P}_{\mathrm{cgw}}$ - capillary pressure, gas-water

$P_{c o w}$ - capillary pressure, oil-water

$\hat{\mathrm{P}}$ - representative capillary pressure

$S$ - saturation

$\sigma \quad$ - interfacial tension

\section{Subscript}

$\begin{array}{ll}g & \text { - gas } \\ \text { gro } & \text { - residual (critical) gas, gas-oil } \\ \text { grw } & \text { - residual (critical) gas, gas-water } \\ \mathrm{mn} & \text { - minimum } \\ \mathrm{mx} & \text { - maximum } \\ o & \text { - oil } \\ \text { org } & \text { - residual oil, gas-oil } \\ \text { orw } & \text { - residual oil, oil-water } \\ \mathrm{r} & \text { - residual or relative } \\ w & \text { - water } \\ \text { wrg } & \text { - residual water, gas-water } \\ \text { wTo } & \text { - residual water, oil-water }\end{array}$

\section{Superscript}

$\begin{array}{ll}* & \text { - normalized, three-phase } \\ \mathrm{n} & \text { - normalized, two-phase } \\ \mathrm{r} & \text { - reference }\end{array}$

\section{References}

1. Skjæveland, S.M. and Kleppe, J.: Recent Advances in Improved Oil Recovery Methods for North Sea Sandstone Reservoirs. SPOR Monograph, Norwegian Petroleum Directorate, Stavanger (1992).

2. Hustad, O.S. and Holt, T.: Gravity Stable Displacement of Oil by Hydrocarbon Gas After Waterflooding. Paper SPE/DOE 24116 presented at the Eighth Symposium on Enhanced Oil Recovery, Tulsa (April 22-24, 1992).

3. Holt, $T$ and Hustad, O.S.: Mechanisms Affecting Residual Oil Saturation. Paper presented at the RUTH seminar, NPD, Stavanger (Dec. 1992).

4. Hustad, O.S.: Residual Oil Saturation - How It May Be Modeled in the Presence of Gas and Water. Paper presented at the Eclipse International Forum, Milan (Sept. 6-9, 1994).

5. Mattax, C.C. and Dalton, R.L.: Reservoir Simulation. SPE Monograph Series, Richardson TX (1990), 13, 135.
6. Baker, L.E.: Three-Phase Relative Permeability Correlations. Paper SPE/DOE 17369 presented at the Enhanced Oil Recovery Symposium, Tulsa (April 17-20, 1988).

7. Bentsen, R.G., 1994: An Investigation into Whether the Nondiagonal Mobility Coefficients which Arise in Coupled, Two Phase Flow are Equal. Transport in Porous Media 14, 23-32.

8. Hustad, O.S.: CERES - An EOS Compositional Reservoir Simulator. IKU Petroleum Research inhouse simulator, Version 10, Trondheim (July, 1994).

9. Coats, K.H.: An Equation of State Compositional Model. SPEJ (Oct. 1980) 363-376.

10. Reid, R.C., Prausnitz, J.M. and Poling, B.E.: The Properties of Gases and Liquids. McGraw-Hill Book Co., Fourth Edition (1988), 642.

11. Firoozabadi, A. and Ramey, H.J., JR.: Surface tension of water-hydrocarbon systems at reservoir conditions. J. Cdn. Pet. Tech. (May-June 1988), $27,3,41-48$.

12. Killough, J.E.: Reservoir Simulation With History-Dependent Saturation Functions. SPEJ (Feb. 1976) 37-48.

13. Holt, T., Hustad, O.S. and Skurdal, H.: Film Flow Mechanisms During Gas Flooding. Paper presented at the Fourteenth IEA Collaborative Project on Enhanced Oil Recovery Workshop and Symposium, Salzburg (Oct. 17-21, 1993).

14. Holt, T., Solbakken, K. and Vassenden, F.: Physical gas/water segregation model - Technical summary report 1994. IKU Petroleum Research report No. 34.2982.00/03/94, Trondheim (Feb. 1995).

\section{Acknowledgment}

The work in this paper was financed by the RUTH Gas Flooding subprogram, supported by The Research Council of Norway, Amerada Hess Norge AVS, Conoco Norway Inc., Den norske stats oljeselskap a.s (Statoil), and Svenska Petroleum A/S. Their financial support is gratefully acknowledged. The authors are also grateful to Dag Wessel-Berg for helpful discussions in preparing this paper. 